\title{
Abordagem psicanalítica da violência contra as mulheres ${ }^{63}$
}

\section{Cândida Sé Holovko ${ }^{64}$}

Neste início de apresentação vou utilizar trechos do romance de Valter Hugo Mãe (2010) "O remorso de Baltazar Serapião", tal como uma vinheta clínica, para colocar em cena o lado cruel das violências domésticas. Neste livro o autor expõe uma organização sociocultural e discursiva de ordem patriarcal na qual um empregado - o narrador desta vinheta - reproduz no ambiente doméstico com sua esposa os mesmos comportamentos desumanos de seu patrão, que dispõe do corpo, do trabalho e da vida daqueles que trata como seus servos, sem a mínima compaixão por suas misérias e suas subjetividades.

“... surpresa com minha aparição gaguejou algo que não ouvi, tão grande foi o ruído de minha mão na sua cara, e tão rápido lhe entornei o corpo ao contrário e lhe dobrei o pé esquerdo em todos os sentidos. que te saiam os peidos pela boca se me voltas a encornar, definharás sempre mais a cada crime, até que sejas massa disforme ... “(p. 53)

“... assim ficou revirada no chão, esfregada de dores corpo todo, a respeitarme infinitamente para se salvar de morrer (...) que o amor era coisa de muito ensinamento. que pena se estropiasse tão nova e depressa como foi chegada à vida do casamento. como eu preferiria que se mantivesse perfeita, para num todo me atrair de fantasias(...), tão louco de paixão estava, tão grande amor lhe tinha..." (p.53)

“...e nada mais era som da sua boca, arredada das palavras por medo grande de morrer. e em dias desses estive eu muito atento a amá-la, rédeas curtas sim, mas amá-la muito mais por sabe-la a retomar o seu lugar, estropiada do pé mas bela de sempre, rosto e figura feminina

\footnotetext{
63 Trabalho apresentado na mesa "Amor e ódio: violência doméstica" no II Simpósio Bienal SBPSP "Fronteiras da Psicanálise: a clínica em movimento" no dia 22 de agosto de 2020.

64 Membro Efetivo e docente da SBPSP, membro do Institute de Psychossomatique Pierre Marty de Paris, ex Co-Chair para a América Latina do COWAP (IPA).
} 
por que me apaixonei, era sem dúvida a minha ermesinda, a minha doce mulher." (p.54) ( grifos meus)

Ao maltratar violentamente sua mulher, Ermesinda, este personagem fictício escancara os vínculos de um mandato de violação imperante há milênios em diferentes culturas como a nossa ocidental, que segundo Segato (2003) refere-se a impulsos agressivos característicos do "sujeito masculino" em direção a quem mostra os signos e gestos da feminilidade" (p. 22).

A minha experiência clínica com analisandas que sofreram violências domésticas me faz pensar que nesses casos, o violador tomado de ódio virulento ao imaginar-se traído, com seu ato impulsivo, pretende escapar do impacto da humilhação narcísica, da vivência de sua vulnerabilidade, recuperando sua falta de poder e sua autoestima pela força. Isto se dá em contextos onde a companheira esboça movimentos de uma subjetividade autônoma, de sua alteridade.

Será casual que neste cenário de violências contra a mulher, Valter Hugo Mãe, utilize, neste livro, várias encarnações do feminino na construção de seus personagens? Vemos a descrição de Ermesinda a mulher idealizada e dócil em sua beleza sem igual. O romancista nos descreve também, o prazer sexual desmesurado de uma outra mulher, a Teresa Diaba, mulher que serve sexualmente todos os homens da pequena aldeia. Surge também na narrativa uma bruxa, mulher que assombra com seus feitiços. Há ainda a esposa do patrão que parece encarnar a grande mãe fálica primordial, senhora da vida e da morte presente no imaginário cultural.

Imagens de mulheres que ameaçam se somam aqui a da mulher ou do feminino convertido em um objeto inferiorizado a ser disciplinado, repudiado, domado, emudecido: - "e nada mais era som da sua boca arredada das palavras".

Referindo-se às violências de gênero contra o feminino, a psicanalista argentina Fiorini (2019) afirma que: "não é somente uma problemática pulsional nem só do complexo de castração masculino, mas se entrelaça com discursos sociais fortemente arraigados, e sua expressão, inclusive em teorias pósfreudianas e contemporâneas, liga-se a uma ordem fálica"(....) "abarca tradições, mitos, imaginários compartilhados que se expressam na vida cotidiana”. 
A analista francesa Aurélie Pfauwadel (2017) ao mencionar o mal-estar na contemporaneidade ligado ao declínio de poder dos homens, conjectura que a afirmação "seja um homem" trata mais de submeter os homens ao modelo patriarcal e fálico vigente por milênios. A desconstrução de referências tradicionais da masculinidade e da feminilidade tem produzido, segundo esta autora, um aumento de crueldade nos movimentos viris que buscam o restabelecimento do androcentrismo como valor narcisista máximo.

As mulheres e as várias "apresentações de gênero" ganharam empoderamento no mundo Ocidental, protegidas por leis que defendem igualdades de direitos. No entanto, vemos cotidianamente escandalosas violações a essas conquistas, como o aumento exponencial de casos de feminicídios, maustratos a mulheres, na maioria negras, crianças e transgêneros, agora em evidência durante os meses da pandemia. Nesta semana foi anunciado na imprensa 180 estupros de mulheres por dia no Brasil e 6 abortos diários de meninas entre 10 e 14 anos!!

A antropóloga Rita Segato (2003, p. 30), na sua pesquisa com homens estupradores, constata na contemporaneidade uma sobreposição de dois sistemas sociais que subjazem os discursos de gênero: "um que eleva a mulher a um status de individualidade e cidadania igual ao homem, e outro que lhe impõe sua tutela" (...) esta última é a regra que rege o gênero e segue demonstrando sua vitalidade inalterada".

Segato ( 2003, p. 46) descreve bem os contextos dessas violências. Diz ela: " em um gesto desesperado por responder ao pai, o sujeito masculino se põe em seu lugar e, ao incorporá-lo - o incorporar a ordem- coloca em cena o abuso em um outro feminino".

Sabemos que as violências domésticas na contemporaneidade não podem ser consideradas, mesmo na psicanálise, como decorrentes simplesmente de patologias individuais, por serem atos intersubjetivos onde participam outros atores reais ou imaginários.

A abordagem psicanalítica enfatiza a importância da escuta atenta e singular a cada uma das experiências traumáticas e fantasias conscientes e inconscientes e as consequências nos corpos e nas subjetividades das pessoas envolvidas nesses delitos, assim como o papel das diferenças culturais no universo da violência de gênero. 
Entre as várias possiblidades de compreensão desses fenômenos, destaco também o que diz o psicanalista Juan Vives (2020), que acredita que a violência do homem está associada ao pavor inconsciente à mulher toda poderosa, representante da mãe primordial que pode engolfá-lo e aniquilá-lo. A compulsão a maltratar sua mulher, segundo este autor, pode ser uma tentativa de submeter, na fantasia e na realidade, a mulher ameaçadora.

\section{Sobre o silêncio das vítimas}

Frequentemente encontramos no contato com mulheres abusadas uma relutância a expor a situação de abuso e a denunciar seu agressor, que não é totalmente explicada pelas violentas ameaças do perpetrador. Acreditamos que a situação traumática disruptiva produziu na mente da mulher uma inundação de excitações, não metaforizadas, que impediram a constituição de uma cadeia representacional que desse conta do vivido, verdadeiros buracos no tecido das representações. Aproximar-se, rememorar algo que não pode ser inscrito como memória verbal, mas ficou marcada no corpo, produz geralmente uma angústia sem nome que leva a mulher abusada ao evitamento do relato.

Acreditamos também que a culpa pelo que foi eliciado em termos de excitação sexual no corpo da mulher também é uma outra fonte que leva ao silêncio das mulheres. Tesone (2005), ao tratar situações de incesto, afirma que o parente incestuoso ao produzir uma excitação corporal não consentida pela mulher-criança abusada, produz um efeito traumático na sua vítima que responde de maneira incontrolada à excitação externa, o corpo se converte ele próprio em corpo externo, que requer ser castigado.

Não é infrequente que muitas mulheres repitam situações de abuso, de autoagressões, de exposição a situações de perigo sexual e acidentes graves. É comum encontrar, na clínica de mulheres violentadas, transtornos alimentares como anorexia e bulimia, além de doenças autoimunes entre outras; patologias estas muito conectadas com vivências profundas de invasão e rompimento do envoltório psíquico e corporal.

Lembremos que muito frequentemente o abusador incestuoso foi também vítima de abusos sexuais muitas vezes intergeracionais em seu ambiente. Durban (2017), analista israelense, refere-se à dinâmica do abusador conceituando-a 
como o "complexo do vitimador". Segundo este autor, sempre que se perturbar a organização precária patológica do abusador, pode surgir a compulsão a evacuar um objeto abusador incorporado em outra pessoa percebida tanto como fraca como ameaçadora (criança, mulher, trans), por escancarar sentimentos infantis de profundo desamparo e também como mecanismo defensivo à angústia de aniquilamento, vivendo ativamente o que foi experimentado anteriormente de modo passivo.

Segundo Durban (2016), situações de incestos contra crianças e adolescentes produzem várias confusões na pessoa violentada: confusão entre criança e adulto; entre os sexos; entre gerações; entre self e objeto; o que é bom, o que é mal; entre o verdadeiro e o falso. Podem surgir angústias muito primitivas tais como o de dissolver-se, diluir-se, romper-se, perder os limites da pele, perder o sentido de orientação, angústias de cair em abismo eterno, ou seja, angústias que não podem ser nomeadas. Essas angústias arcaicas ameaçam a constituição do Ego ligado ao tempo, ao espaço e aos vínculos amorosos.

Para finalizar, retomo agora, as palavras de Ugo Mãe do início desta apresentação, muitas vezes ouvidas por homens que cometeram violência doméstica com suas companheiras: "tão louco de paixão estava, tão grande amor lhe tinha".

Podemos dizer que isso é amor?

Para mim, amor é o que diz o filósofo Alain Badiou (2009), no seu livro Elogio do amor:

"É no amor que o sujeito vai mais além de si mesmo, mais além do narcisismo" pg. 24 (...) "No amor há uma separação ou disjunção que pode ser simplesmente a diferença entre duas pessoas e suas subjetividades infinitas...” (pg. 31). 


\section{Referências}

Alizade, A. M. (2005). "Incest: the damaged psychicflesh" in Giovanna Ambrosio (ed.), On Incest: Psychoanalytical Perspectives. London and New York: Karnac, 101-14.

Alizade, M. (2011). "O Incesto Verbal" in Rev. Psicanalítica, vol. XII, n. 1 Rio de Janeiro; 17-26.

Badiou, A. (2009). Éloge de L’amour. Flammarion, Paris.

Benjamin. J. (2020). Vulnerabilidad, Repudio e Violencia. A tragédia da Masculinidad. Texto apresentado no XIV Diálogo Latinoamericano Intergeneracional entre Hombres y Mujeres Comité Mujeres y Psicoanálisis de la IPA / COWAP 24 y 25 de abril, D.F. México "Poder, Género y Amor: Perspectivas femeninas contemporáneas".

Freud S. ed. Standard Brasileira das Obras Psicológicas Completas de Sigmund Freud, ed. Standard Brasileira, Editora Imago, 1969, Rio de Janeiro.

(1910). Um tipo especial de Escolha de Objeto feita pelos homens.

Contribuição à Psicologia do Amor I

(1912). Sobre a tendência universal à depreciação na esfera do amor.

Contribuições à Psicologia do Amor II

(1918-17). O Tabu da Virgindade. Contribuição à psicologia do Amor

III

(1914). Sobre o Narcisismo. Uma Introdução

Glocer Fiorini, L. (2019). Hacia una desconstrucción de "lo feminino": Discursos, Lógicas y Poder. Implicancias teórico-clínicas In Revista de Psicoanalisis (APA), tomo LXXVI, n.1, Buenos Aires.

Mãe, V. H (2010). O remorso de Baltazar Serapião. Editora 34, São Paulo.

Pfauwadel,A. (2017) Virilités Plurielles In La Cause du désir. Revue de psychanalyse-Virillités .Paris

Rosenberg, Benno (1991). Masoquismo Mortífero y Masoquismo Guardián de la Vida. Tradução, Silvia Pérez- Galdós, Promolibro, Valencia ,1995.

Segato, R. L. (2003). Las estruturas elementales de la Violencia. Bernal, Universidad nacional de Quilnes, Buenos Aires.

Tesone, Juan (2005). Incesto: El Cuerpo Robado. Trabalho apresentado no $2^{\text {a }}$ COWAP European Conference on Incest (IPA). Lisboa, 21 e 22 Março 2005.

Vives, J. (2020). La Violencia em los hombres. Comentário a apresentação do texto de Jessica Benjamin no XIV Diálogo Latinoamericano Intergeneracional entre Hombres y Mujeres Comité Mujeres y Psicoanálisis de la IPA / COWAP 24 y 25 de abril, D.F. México "Poder, Género y Amor: Perspectivas femeninas contemporáneas". 